\title{
Efeitos Terapêuticos de Oficinas Dialógicas: a Fala em Contexto de Reforma Psiquiátrica
}

\author{
Bruno Henrique Soares ${ }^{1}$ \\ ${ }^{1}$ Universidade Estadual da Paraíba, PB, Brasil. \\ Farah Catharine de Queiroz Silva ${ }^{1}$ \\ ${ }^{1}$ Universidade Estadual da Paraíba, PB, Brasil. \\ Pablo Leonardo de Melo $^{1}$ \\ ${ }^{1}$ Universidade Estadual da Paraíba, PB, Brasil.
}

\author{
Andréa Xavier de Albuquerque de Souza ${ }^{1}$ \\ ${ }^{1}$ Universidade Estadual da Paraíba, PB, Brasil. \\ Márcia Candelaria da Rocha ${ }^{1}$ \\ ${ }^{1}$ Universidade Estadual da Paraíba, PB, Brasil. \\ Viviane Almeida Cavalcanti ${ }^{1}$ \\ ${ }^{1}$ Universidade Estadual da Paraíba, PB, Brasil.
}

Resumo: Entre 2013 e 2014, estudantes de Psicologia da Universidade Estadual da Paraíba iniciaram o ciclo de 25 Oficinas Terapêuticas Dialógicas com grupo de usuários do Centro de Atenção Psicossocial II - Novos Tempos, da cidade de Campina Grande-PB. Quase dois anos após seu término, retornou-se à instituição com objetivo de apreender, em usuários participantes, a função terapêutica destas intervenções. Utilizou-se Técnica de Documentação Direta em Pesquisa de Campo Exploratória. A coleta de dados ocorreu com aplicação de entrevista semiestruturada a quatro usuárias e suas quatro Técnicas de Referência, com dados tratados pelo software de análise lexical Iramuteq. Estes foram interpretados à luz de publicações do Ministério da Saúde e Conselho Federal de Psicologia acerca das orientações à atuação em Políticas Públicas de Saúde Mental, bem como das contribuições de teorias psicanalíticas. A Análise de Classificação Hierárquica Descendente e a Análise Fatorial de Correspondência identificaram posicionamento e estruturação de palavras no material, cujos gráficos apontam a fala nas oficinas com função terapêutica principal de servir enquanto veículo à expressão/manutenção da subjetividade em âmbitos individual e social nos contextos intra e extra CAPS, bem como reconhecimento de que a adesão do usuário não depende apenas de seu comprometimento psíquico junto ao tratamento, mas também das formas de estabelecimento de vínculos terapêuticos com a equipe técnica. $\mathrm{O}$ acesso ao contexto de Reforma Psiquiátrica mostra necessidade de diálogos constantes voltados à Saúde Mental e Luta Antimanicomial, fomentando alcance de práticas que tragam possibilidades de atuação e pesquisa que melhor respondam às demandas na comunidade.

Palavras-chave: Saúde Mental. Clínica Ampliada. Terapêutica Psicanalítica. Compromisso Social. Intervenção Psicossocial. 


\title{
Therapeutic Effects of Dialogical Workshops: the Voice in the Context of Psychiatric Reform
}

\begin{abstract}
Between 2013 and 2014, Psychology students from Universidade Estadual da Paraíba started the cycle of 25 Dialogical Therapeutic Workshops with a group of users in Centro de Atenção Psicossocial II - Novos Tempos, in Campina Grande, Brazil. Almost two years after its finishing point, they returned to the institution with the aim of apprehending, on users participants, the therapeutic function of those interventions. Direct Documentation Technique in Exploratory Field Research was used. Data collection was performed with application of a semi-structured interview to four users and their Reference Team, and data were processed by Iramuteq, a lexical analysis software. Data were interpreted in the light of publications from Ministério da Saúde and Conselho Federal de Psicologia on the strategies to work in Public Mental Health Policies, as well as in the light of contributions of psychoanalytic theories. The tests "Descending Hierarchical Analysis" and "correspondence factor analysis" identified positioning and structuring of words in the material, whose graphs indicate the speech in the workshops with the main therapeutic function of serving as a vehicle for the expression and maintenance of subjectivity in individual and social contexts, into and out of the psychosocial care center, as well as the recognition that the users' adherence depends not only on their psychic commitment to the treatment, but also on the ways of establishing therapeutic relations with the technical team. The access to the context of the Brazilian Psychiatric Reform shows the need for constant dialogues on Mental Health and the Antiasylum Movement, encouraging a range of practices that bring possibilities of action and research that best meet the demands in the community.
\end{abstract}

Keywords: Mental Health. Expanded Clinic. Psychoanalytic Therapy. Social Commitment. Psychosocial Intervention. 


\title{
Efectos Terapéuticos de Talleres Dialógicos: el Discurso en el Contexto de la Reforma Psiquiátrica
}

\begin{abstract}
Resumen: Entre 2013 y 2014, los estudiantes de psicología de la Universidad Estatal de Paraíba comenzaron el ciclo de 25 Talleres Terapéuticos Dialógicos con un grupo de usuarios del Centro de Atención Psicosocial II - Novos Tempos, en la ciudad de Campina Grande-PB. Casi dos años después de su finalización, fue devuelto a la institución para aprehender, en los usuarios participantes, la función terapéutica de estas intervenciones. La técnica de Documentación Directa se utilizó en la Investigación de Campo Exploratoria. Los datos se recopilaron a través de entrevistas semiestructuradas con cuatro usuarias y sus cuatro Técnicas de Referencia, con datos procesados por el software de análisis léxico Iramuteq. Estos fueron interpretados a la luz de las publicaciones del Ministerio de Salud y el Consejo Federal de Psicología sobre las pautas para actuar en las Políticas Públicas de Salud Mental, así como las contribuciones de teorías psicoanalíticas. El Análisis de Clasificación Jerárquica Descendente y el Análisis del Factor de Correspondencia identificaron el posicionamiento y la estructuración de las palabras en el material, cuyos gráficos señalan el discurso en los talleres con la función terapéutica principal de servir como vehículo para la expresión/ mantenimiento de la subjetividad en contextos individuales y sociales en contextos intra y extra CAPS, así como el reconocimiento de que la adherencia del usuario depende no solo de su compromiso psíquico con el tratamiento, sino también de las formas de establecer vínculos terapéuticos con el equipo técnico. El acceso al contexto de la Reforma Psiquiátrica muestra la necesidad de diálogos constantes centrados en la Salud Mental y la Lucha Antimanicomial, promoviendo el alcance de prácticas que brinden posibilidades de acción e investigación que respondan mejor a las demandas de la comunidad.
\end{abstract}

Palabras clave: Salud Mental. Clínica Extendida. Terapia Psicoanalítica. Compromiso Social. Intervención Psicosocial.

\section{Introdução}

Ao longo das últimas quatro décadas, a Reforma Psiquiátrica convida estudantes e profissionais das áreas 'Psi' ao estabelecimento de diálogos em nível multi, inter e transdisciplinar, com a finalidade de repensar as práticas em Saúde Mental na contemporaneidade. A partir desta perspectiva, entre os anos de 2013 e 2014, estudantes do curso de Psicologia da Universidade Estadual da Paraíba deram início a um ciclo de 25 Oficinas Terapêuticas junto a um grupo de usuários do Centro de Atenção Psicossocial II Novos Tempos, da cidade de Campina Grande-PB. A proposta foi suscitada a partir dos componentes curriculares Extensão I e II, no segundo e terceiro anos da graduação em Psicologia, cuja ênfase de trabalho pautou-se na perspectiva de Clínica Ampliada, sob orientação e supervisão da Professora MS. Márcia Candelaria da Rocha e participação de sete estudantes extensionistas ao longo do projeto. Assim, buscou-se abertura de espaço à expressividade dos usuários participantes, apresentando disparadores temáticos, como desenhos e objetos, para que através da fala suas histórias fossem contadas e conflitos ressignificados. Após 10 oficinas, deu-se a devolutiva aos usuários e Técnicos de Referência responsáveis pelos Projetos Terapêuticos dos participantes. No entanto, houve a renovação do projeto de extensão, cujo desenvolvimento expressou-se em mais 15 oficinas dialógicas, até dezembro de 2014.

Passando-se quase dois anos de seu término, houve a compreensão da necessidade de retorno à instituição, em caráter de pesquisa de campo, com objetivo de apreender, em usuários participantes das oficinas dialógicas entre outubro de 2013 e dezembro de 2014, a função terapêutica proveniente destas intervenções. Para atingir este objetivo, buscou-se conhecer como usuárias e suas respectivas Técnicas de Referência se aperceberam neste processo, bem 
como os principais elementos que se constituíram enquanto norteadores do tratamento, relacionados às oficinas. Deste modo, espera-se que os avanços nesta modalidade de estudo apontem aos possíveis novos direcionamentos práticos e teóricos, testando os acertos e erros de apostas interventivas, enquanto tentativa de responder às demandas de sofrimento trazidas pelos usuários. Assim, sob esta ótica, compreende-se a indispensabilidade de problematizar o papel da Psicologia no âmbito da Saúde Mental, cuja prática conceba o humano enquanto ser biopsicossocial, e discutir a utilização de oficinas terapêuticas dialógicas como instrumento de operacionalização viável. Ademais, espera-se que este estudo mantenha acesas as luzes emitidas pelo compromisso social, elemento basilar ao desenvolvimento da profissão, enquanto ciência e prática.

\section{Reforma Psiquiátrica no Brasil e implantação dos equipamentos substitutivos em saúde mental}

Em 1970, deu-se início ao Movimento Sanitário no Brasil, cujo objetivo se centralizava em mudanças na atuação e gestão dos meios de acesso à saúde pública. Contemporaneamente, no ano de 1978, a Reforma Psiquiátrica surgia enquanto luta pelos direitos dos pacientes psiquiátricos, com a união de profissionais da área, familiares, pacientes que sofriam em decorrência de várias internações sem êxito no tratamento e sindicalistas. Criticavam-se os moldes de tratamentos adotados, como o modelo hospitalocêntrico, com inspiração nos avanços alcançados através da revolução em Saúde Mental, na Itália (Mello, Mello, \& Kohn, 2007).

Neste contexto, pela primeira vez, surge em São Paulo um Centro de Atenção Psicossocial (CAPS), junto à eclosão de denúncias de maus tratos e desumanidade dentro de hospitais psiquiátricos do país. Iniciou-se, assim, um modelo inovador de aplicação clínica, como proposta de substituição ao modelo clássico até então adotado. Posteriormente, em 1989, foram criados, em Santos, Núcleos de Atenção Psicossocial, com funcionamento de 24 horas. Estas instituições assemelham-se às conhecidas residências terapêuticas, com atendimento voltado àqueles que saíam dos hospitais. Deste modo, a partir da eficiência e viabilidade de novos modelos de atuação, levou-se ao congresso a proposta de regulamentação dos direitos de pessoas com transtornos mentais, além da extinção dos hospitais psiquiátricos, um ano após a instituição do Sistema Único de Saúde - SUS (Mello et al., 2007).

No entanto, ainda de acordo com Mello et al. (2007), apenas a partir de 1992 foi aprovada a substituição progressiva do modelo anterior por uma ampla rede integrada de atenção à Saúde Mental. Em 2001, sancionou-se a lei do deputado Paulo Delgado, cuja tramitação no congresso durou 12 anos para regulamentar a modalidade de assistência em Saúde Mental com o oferecimento de tratamentos dentro da própria comunidade do usuário, estabelecendo seus direitos. Assim, ainda no mesmo ano, ocorreu a III Conferência Nacional de Saúde Mental que contou com o engajamento de 23 mil brasileiros, entre funcionários, familiares, usuários e profissionais de saúde, conferindo ao CAPS o valor energético pra mudança do modelo de assistência.

Em relação à eficiência e agilidade de instituição do novo modelo, a cidade de Campina Grande-PB é considerada uma referência na reorganização dos serviços disponíveis e implantação de novos aparelhos. O município realizou, a nível regional, um encontro cuja pretensão era avaliar a situação da assistência psiquiátrica junto a outras cidades. Sua mudança nos moldes de assistência psiquiátrica ocorreu em um ano, iniciativa bastante benéfica aos usuários (Mello et al., 2007).

\section{Inserção dos CAPS nas Políticas Públicas de Saúde Mental e Oficinas Terapêuticas: uma aposta diferenciada de acolhimento}

No contexto da Reforma Psiquiátrica que se instituía no país, os CAPS tiveram papel essencial e estratégico enquanto aparelhos substitutivos dos leitos psiquiátricos de grandes hospitais dedicados a esta assistência. Ficou-lhe designado o acolhimento àqueles com sofrimento mental, com preservação dos laços familiares e comunitários, além do empoderamento destes enquanto autores do próprio tratamento (Mello et al., 2007). Desta forma, a Portaria $\mathrm{n}^{\circ}$ 336/GM, de 19 de fevereiro de 2002, regulamenta os CAPS como serviço substitutivo e parte integrante do SUS, além de reconhecer e ampliar o funcionamento e a complexidade deste serviço.

Dentre as atividades coletivas, destacam-se as oficinas terapêuticas. Estas, a partir de atividades artísticas à valorização do potencial criativo, imaginativo e expressivo do usuário, possibilitam a projeção 
de conflitos internos e externos, além do fortalecimento da autoestima e diversificação de saberes e a expressão da subjetividade do sujeito. Estas oficinas podem ser vistas como modalidade de intervenção por possibilitarem ao usuário a fala, a expressão e o acolhimento, em direção a sua reabilitação (Azevedo, \& Miranda, 2011).

Estas oficinas trazem uma visão de como a "loucura" pode ser vista e vivenciada, com novo conjunto de ações e ideias trazidas pela inovação da Reforma Psiquiátrica, cujo investimento ocorre a partir de atualizações e reinterpretações das práticas, para que sua eficácia se torne produtiva e crescente no amparo das diversas formas de sofrimento mental.

\section{Psicanálise, expressividade e movimento catártico: oficina terapêutica dialógica enquanto veículo do processo de ressignificação subjetiva}

A Psicanálise é compreendida como método de exploração dos conteúdos do Inconsciente, apontando ao modo de funcionamento subjetivo do sujeito. Nessa perspectiva, Freud (1989) indica que, através do discurso, o processo de atualização dos conteúdos reminiscentes proporciona a ressignificação, meta almejada na execução das oficinas terapêuticas onde há a lida com afetos que emergem em fragmentos. Através da ressignificação, busca-se o efeito reconfortante pela via da verbalização e da expressividade.

Assim, complementando o pensamento postulado por Freud, Lacan opera, com maior ênfase, no recorte psicanalítico da palavra, ao apontá-la como veículo através do qual "[...] o Inconsciente encontra sua articulação essencial” (Dor, 1989, como referido em Gomes, 2009). Tendo em vista a necessidade da palavra, ressalta-se que é pela via da verbalização que as oficinas terapêuticas dialógicas se pautam, trazendo aos usuários a possibilidade de expressividade, contando com espaço que permita a ressignificação de conteúdos a partir da fala.

Considerando a importância da inserção do indivíduo na sociedade, Gomes (2009) ressalta que comunicação e sociedade são conceitos indissociáveis na Psicanálise. Seguindo raciocínio semelhante, Campos (2007) destaca que há a necessidade da construção através da expressividade, movimento em que o indi- víduo se estende ao outro através da linguagem elucidando as próprias questões.

\section{Metodologia}

O desenvolvimento se deu em Pesquisa de Campo do tipo Exploratório e qualitativo. Segundo Marconi e Lakatos (2008), utiliza-se este desenho a fim de alcançar informações e/ou conhecimentos acerca de um problema, possibilitando a descoberta de novos fenômenos ou relações entre eles. Sua realização ocorreu em uma unidade do Centro de Atenção Psicossocial II, localizado na cidade de Campina Grande-PB, com população alvo dividida em dois grupos. O primeiro, composto por quatro usuárias do CAPS, enquanto o segundo composto por suas respectivas Técnicas de Referência (TR). Enquanto critérios de inclusão à participação das usuárias, compreendeu-se a necessidade do registro de presença em oficinas terapêuticas, com participação mínima em cinco encontros e capacidade de verbalização clara. Em relação às TR, enfatiza-se a indispensabilidade de ter acompanhado, continuamente, as usuárias participantes das oficinas, entre outubro de 2013 e dezembro de 2014, além da assistência contínua, entre 2015 e 2016. Já os critérios de exclusão, quanto à participação das usuárias, consideram-se o não comparecimento em oficinas, presença inferior a cinco encontros e dificuldade de verbalização clara. Em relação às TR, menciona-se o não acompanhamento contínuo das usuárias participantes das oficinas, entre outubro de 2013 e dezembro de 2014 e o não apoio assistencial frequente destas, entre 2015 e 2016.

Desta forma, quatro usuárias e suas respectivas TR responderam à entrevista, como demonstram os dados sociodemográficos dispostos nas Tabelas 1 e $2^{1}$.

Concebeu-se a importância da utilização de entrevista semiestruturada, inicialmente em sua versão piloto, como instrumento indispensável à coleta de dados e apreensão acurada do conteúdo trazido por sujeito participante. Sob esta perspectiva, os dados trazidos por usuárias e TR foram tratados através do software de análise lexical Iramuteq (Interface de $R$ pour les Analyses Multidimensionnelles de Textes et de Questionnaires), em sua versão 0.7.2.0, no qual foram inseridos os dados brutos das falas das participantes para identificar o posiciona-

${ }^{1}$ Cada usuária e sua respectiva TR receberam o mesmo número de identificação. 
Tabela 1.

Caracterização sociodemográfica das usuárias respondentes.

\begin{tabular}{|c|c|c|c|c|c|}
\hline $\begin{array}{l}\text { DADOS } \\
\text { USUÁRIAS }\end{array}$ & Idade & Escolaridade & Profissão & $\begin{array}{l}\text { Renda familiar } \\
\text { (R\$) }\end{array}$ & $\begin{array}{l}\text { Tempo de utilização } \\
\text { do Centro de Atenção } \\
\text { Psicossocial }\end{array}$ \\
\hline 1 & 47 & Fund. Incompleto & Artesã & 260,00 & 11 anos \\
\hline 2 & 44 & Alfabetização & - & 200,00 & 7 anos \\
\hline 3 & 55 & Ensino Médio & - & 400,00 & 8 anos \\
\hline 4 & 47 & Fund. Incompleto & - & 300,00 & 11 anos \\
\hline
\end{tabular}

Tabela 2.

Caracterização sociodemográfica das Técnicas de Referência (TR) respondentes.

\begin{tabular}{|c|c|c|c|c|c|}
\hline $\begin{array}{l}\text { DADOS } \\
\text { TR }\end{array}$ & Idade & Escolaridade & Profissão & $\begin{array}{c}\text { Renda mensal } \\
\qquad(\mathrm{R} \$)\end{array}$ & $\begin{array}{c}\text { Tempo de atuação no } \\
\text { Centro de Atenção } \\
\text { Psicossocial }\end{array}$ \\
\hline 1 & 36 & Ensino Técnico & $\begin{array}{c}\text { Técnica em } \\
\text { Enfermagem }\end{array}$ & 1.800 & 12 anos \\
\hline 2 & 46 & Ensino Superior & Psicóloga & 8.000 & 8 anos \\
\hline 3 & 34 & Ensino Superior & Pedagoga & 1.500 & 3 anos \\
\hline 4 & 34 & Ensino Superior & Pedagoga & 1.500 & 3 anos \\
\hline
\end{tabular}

mento e a estruturação de palavras no material, de modo que indicadores e visualizações de gráficos auxiliaram à compreensão dos conteúdos existentes nos ambientes do texto. Assim, segundo Camargo e Justo (2013), por tratar-se de dados essencialmente linguísticos, este software se mostra relevante em estudos sobre pensamentos, crenças e opiniões advindas de conteúdo simbólico evocado em relação a algum fenômeno. Estes dados foram interpretados à luz das Políticas Públicas de Saúde Mental, cujas diretrizes se encontram em publicação do Ministério da Saúde do Brasil (2004), além das normativas do Conselho Federal de Psicologia para o trabalho do psicólogo neste âmbito. Acrescenta-se, ainda, a interpretação dos dados a partir das teorias psicanalíticas, e discussão enriquecida com contribuições de áreas afins como a Filosofia e a literatura de Intervenções Psicossociais.

A coleta dos dados ocorreu após contatar usuárias participantes das oficinas terapêuticas, bem como as respectivas TR. Assim, junto a esta população, discutiu-se a possibilidade de aplicação da entrevista e do registro de áudio, com apresentação do Termo de Consentimento Livre e Esclarecido, do Termo de Autorização para Gravação de Voz, além do
Termo de Autorização Institucional para viabilização da coleta de dados. Buscou-se, deste modo, assegurar às participantes alguns princípios éticos como os de sigilo e anonimato, com utilização dos dados única e exclusivamente para esta pesquisa, além do direito de ter acesso às informações coletadas ou de desistir do processo a qualquer momento sem qualquer forma de ônus, conforme a Resolução $n^{\circ} 466$ CNS/MS (2012), responsável pelas diretrizes acerca de pesquisas com seres humanos, em Saúde. Considera-se que esta pesquisa ofereceu riscos mínimos àquelas que consentiram suas participações. Por se tratar de um estudo em Psicologia, cujo processo de coleta de dados se deu através de entrevista, existiu a evocação de afetos, sentimentos ou lembranças que podem causar ansiedade ou outra forma de desconforto subjetivo, já que parte da população entrevistada falou sobre sua experiência de vida ao longo do período em que recebe(eu) tratamento psicológico em um serviço de Saúde Mental. No entanto, reafirmou-se o compromisso ético de zelar pelo bem-estar das participantes, interrompendo a entrevista, quando necessário, para oferecer acolhimento no formato escuta psicológica, deixando-as à vontade para participar ou não da pesquisa, bem como desis- 
tir do processo a qualquer momento. Já em relação aos benefícios, cita-se a possibilidade de as participantes obtê-los de modo direto, a exemplo da autorreflexão acerca do próprio histórico terapêutico pelo qual cada pessoa passou, bem como de modo indireto, contribuindo ao aprimoramento de novas práticas em Psicologia no serviço em que a participante da pesquisa recebe/recebeu atendimento.

\section{Pesquisa-ação, Psicologia e compromisso social na Esfera da Saúde Mental}

Concorda-se com o pensamento de Martínez (2009) ao mencionar que o psicólogo, na sua condição de sujeito, revela-se como elemento central na discussão do compromisso social da Psicologia. Nesta perspectiva, considerando a Reforma Psiquiátrica, pode-se advogar acerca da urgência de pesquisas científicas que promovam um metaolhar direcionado ao aperfeiçoamento de atuações profissionais, com objetivo de suscitar discussões que possam operar no advento contínuo de novas práticas, em Saúde Mental, no contexto CAPS.

Assim, considera-se que o desenvolvimento de oficinas terapêuticas dialógicas, junto a usuários do CAPS II, caracterizou-se enquanto um fazer ético e compromissado socialmente, cuja operacionalização das atividades se destacou pelo viés da ação. Ademais, cita-se que esta ação, em extensão, apresentou potencial de pesquisa, na medida em que produziu saberes e conhecimentos aos extensionistas acerca do contexto acessado. Deste modo, com base na experiência passada de extensão que redundou empiricamente em um estudo científico, chama-se atenção à pertinência da realização de uma pesquisa que tenha, por si só, o poder de produzir efeitos no pesquisado, caracterizando-se enquanto pesquisa-ação. Acredita-se, enquanto resposta à/ao questão/compromisso ética(o) levantada(o), que a contribuição de pressupostos da Pesquisa-ação melhor responda às necessidades metodológicas deste estudo, já que esta perspectiva científica pode se constituir como um meio de formação e mudança participativa, como indica Jesus (2010). Portanto, a partir da dialética em que ação vira pesquisa e pesquisa vira ação, sugere-se a importância desta nova inscrição do pesquisador em campo, cuja participação ativa no processo de coleta e análise de dados, bem como no processo de devolutiva dos resultados e promoção de mudanças, em determinada realidade local, se faz necessária.

\section{Descrição e Discussão dos Resultados}

Para alcançar os resultados descritos, realizou-se a criação de dois corpora textuais, a partir da divisão do material de verbalizações transcritas de usuárias e de Técnicas de Referência, respectivamente. $\mathrm{Na}$ sequência, foram inseridos no software com função de executar análise lexical de cada corpus da amostra. De acordo com Camargo e Justo (2013), tal procedimento viabiliza a realização do teste de Análise Hierárquica Descendente (CHD), proposto por Reinert, em que segmentos de texto (trechos de falas) são classificados de acordo com seus respectivos vocabulários e seus conjuntos repartidos em formas reduzidas. Assim, esta análise objetiva a obtenção das categorias de Unidades de Contextos Elementares (UCE), indicando vocabulários semelhantes entre si e diferentes das UCE de outras categorias. Ademais, acrescenta-se a segunda forma de apresentação destes resultados no formato de Análise Fatorial de correspondência (AFC), feita a partir da CHD de cada corpus textual com a construção de um gráfico com eixos e quadrantes que exibem as palavras associadas às suas respectivas categorias. Após a inserção do corpus textual no software, referente às falas das usuárias com respostas às questões da entrevista, indicam-se na Tabela 3 os dados de saída que subsidiaram a construção de sua CHD e da AFC.

Assim, a partir da CHD, foi gerado um dendograma que organizou falas relacionadas aos elementos norteadores das oficinas em cinco categorias dispostas na Figura 1.

Na Figura 1, observa-se que o dendograma apresenta as partições feitas no corpus até que as categorias finais fossem alcançadas. Assim, o corpus Usuárias teve sua primeira partição em dois

Tabela 3.

Dados do software correspondentes ao corpus textual das falas de usuárias.

\begin{tabular}{lc}
\hline DADOS & TOTAL \\
\hline Número de textos & 4 \\
Número de segmentos de textos & 164 \\
Número de formas distintas & 1.008 \\
Número de ocorrências & 5.500 \\
Média das formas por segmento & 33,53 \\
Número de categorias & 5 \\
Retenção de segmentos de texto & $110(67,07 \%)$ \\
\hline
\end{tabular}


subcorpus, os quais indicam a existência de dois grupos principais de elementos norteadores das oficinas, para as respectivas respondentes. O primeiro deles é composto pelas categorias 1 (Percepção da proposta/17,3\%) e 4 (Religiosidade/20\%), as quais passam pela segunda partição que dá origem à categoria 5 (Autopercepção /27,3\%). Neste grupo, observa-se a existência da circularidade de falas que sugerem a promoção das oficinas enquanto espaços à emergência de fatores afetivos e emocionais, através da fala, como balizadores do processo terapêutico em que ocorrem alívio da tensão psíquica e reflexão, destacando-se estes segmentos textuais: "Aqui a gente desabafa as coisas com o outro e, em casa, a gente não... não. Às vezes, não tem gente pra gente desabafar. E, aqui, tem... pra gente desabafar. Mesmo a gente fazendo a oficina, mesmo tendo dez pessoas, a gente desabafa" (Categoria 1, Usuária 2).
"Né que a gente seja melhor do que ninguém não. [...] a gente tem que ser humilde de espírito, né?" (Categoria 4, Usuária 1). “[...] nos dias em que vocês vinham, eram outras coisas diferentes. Eram [...] outros trabalhos, [...] dinâmicas. A gente brincava, a gente pensava" (Categoria 5, Usuária 4).

O conteúdo dos segmentos supracitados abre possibilidade à verificação da literatura psicanalítica que corrobora a função catártica da fala. Assim, Breuer e Freud (1995) obtiveram relatos de uma paciente que descrevia o método da fala como talking cure ${ }^{2}$, referindo-se a este também como o processo em que ocorre chimney-sweeping ${ }^{3}$. Neste ensejo, acrescenta-se que "o objetivo maior [...] da rede substitutiva é acolher e resgatar a subjetividade de cada um e, ao mesmo tempo, possibilitar a construção de redes relacionais e de convivência social" (Conselho Federal De Psicologia [CFP], 2013, p. 68).

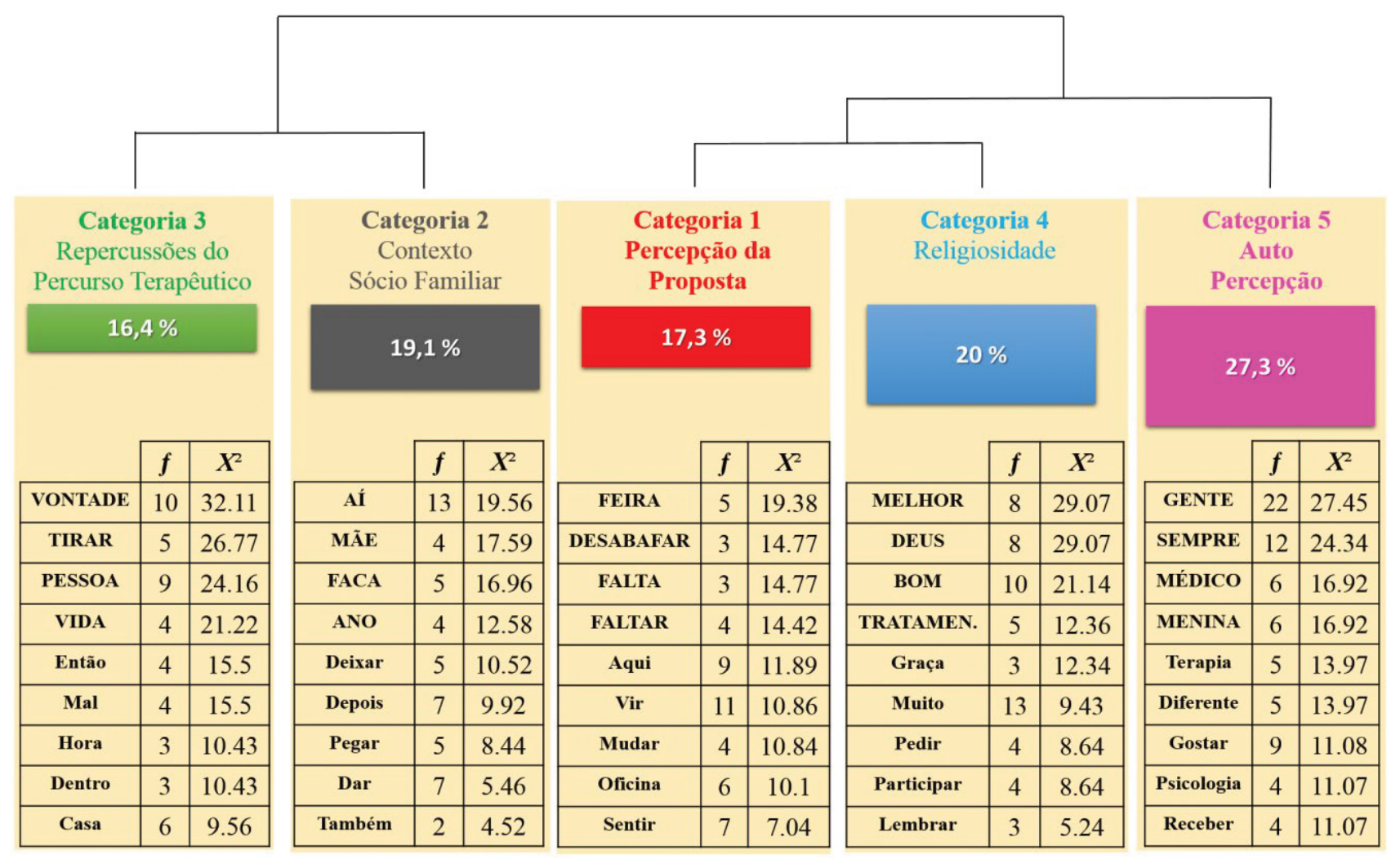

Figura 1.

Dendograma das categorias relacionadas aos elementos norteadores das oficinas, segundo as usuárias, gerado a partir da inserção de corpus textual das falas no Iramuteq.

\footnotetext{
${ }^{2}$ Cura pela fala.

${ }^{3}$ Limpeza da chaminé.
} 
Já o segundo grupo é composto pelas categorias 3 (Repercussões do percurso terapêutico/16,4\%) e 2 (Contexto sociofamiliar /19,1\%). Neste caso, identificam-se falas cujo contexto sugere família e tratamento enquanto fatores indissociáveis, como apontam os segmentos:

[...] Aí eu tava querendo, assim... não só querendo tirar minha vida, mas do próximo, né? Dava vontade de furar as pessoas. [...] as pessoas que eu gostava mais eram as que eu mais tinha vontade de enfiar a faca. Eu tinha vontade de sair correndo. Tinha noite d'eu ir dormir duas horas, fumando cigarro só pensando em fazer o mal. [...] Se eu pegar assim... um lápis [...], uma caneta ou se estiver com alguma coisa já vem aquela maldade de... da... do meu pensamento [...]. Sobre a vontade de matar as pessoas, melhorou agora (Categoria 3, Usuária 2).

"[...] e ela e eu ainda estava na fase de recuperação e eu já ia escrevendo. Eu nem sabia o que fazia e escrevi também pra ela." (Categoria 3, Usuária 4). "[...] às vezes, eu entro em crise, sabe? Quero entrar em crise, aí meu filho: 'Mainha não fique assim, não! Mainha, não fique assim [...]'” (Categoria 2, Usuária 1). "[...] a vontade era grande. Aí, eu falei pra minha irmã de criação [...], eu pedi pra minha filha pra me amarrar de noite. Aí, ela pergunta o porquê. Aí, eu disse" (Categoria 2, Usuária 2).

Sobre o contexto trazido por este grupo de categorias, a literatura de Políticas Públicas de Saúde Mental lembra a importância de o serviço substitutivo manter posição dialogante com atores que compõem a rede de laços sociais do usuário, a exemplo da família (Coelho, Velôso, \& Barros, 2017). Esta, segundo Brasil (2004), é muitas vezes considerada o elo mais próximo que o usuário estabelece com o mundo, justificando sua inclusão no Projeto Terapêutico também como uma parceira no tratamento, acrescentando-se as possibilidades de acompanhamentos em grupos de famílias ou através de atendimento individualizado a esta.

A seguir, na Figura 2, vislumbra-se o gráfico de $\mathrm{AFC}$ referente às palavras-chave acerca dos elementos norteadores das oficinas, nos discursos trazidos pelas usuárias, em que segundo Camargo e Justo (2013), organiza em plano cartesiano os diferentes vocábulos que representam o posicionamento das categorias no corpus textual, o que possibilita a visualização daquelas que se complementam e concentram seus corpora, bem como daquelas que se distanciam do centro com desdobramentos mais específicos. Neste caso, aprecia-se o gráfico de AFC na perspectiva em que a linha do eixo horizontal divide as categorias a partir da noção de percepção dos meios, cujo bloco superior (quadrantes 1 e 2) indica a concentração da apreensão do meio externo, com composição a partir das categorias 4 (Religiosidade) e 2 (Contexto Sociofamiliar), cujos endereçamentos das falas são feitos aos ambientes e/ou atores de convívio próximo. Enquanto isso, o bloco inferior (quadrantes 3 e 4) indica a concentração da apreensão do meio interno, com composição a partir das categorias 5 (Autopercepção) e 3 (Repercussões do Percurso Terapêutico), com endereçamentos das falas das usuárias voltados a si próprias. Já a linha do eixo vertical divide as categorias a partir da noção de percepção das relações, cujo bloco esquerdo (quadrantes 1 e 3 ) indica a concentração da apreensão em nível individual, com composição a partir das categorias 4 (Religiosidade) e 5 (Autopercepção), com falas autodirecionadas das respondentes. E o bloco direito (quadrantes 2 e 4) indica a concentração da apreensão em nível social, com composição a partir das categorias 2 (Contexto Sociofamiliar) e 3 (Repercussões do Percurso Terapêutico), cujos segmentos textuais apontam às falas direcionadas principalmente àqueles junto aos quais se mantém convívio social.

Ademais, como demonstrado ainda na Figura 2 , observa-se que todas as categorias dialogam entre si, com destaque à categoria 1 (Percepção da Proposta) que se localiza no centro do gráfico com maiores pontos de ligação entre os quadrantes dos eixos horizontal e vertical, cujos discursos das respondentes estão relacionados à expressividade através da fala.

No que se refere aos dados das TR, após a inserção do corpus textual no software com respostas às perguntas da entrevista, indicam-se na Tabela 4 os dados de saída que subsidiaram a construção de sua CHD e da AFC.

Assim, a partir da CHD, foi gerado um dendograma que organizou falas relacionadas aos elementos norteadores das oficinas em cinco categorias, como mostra a Figura 3. 


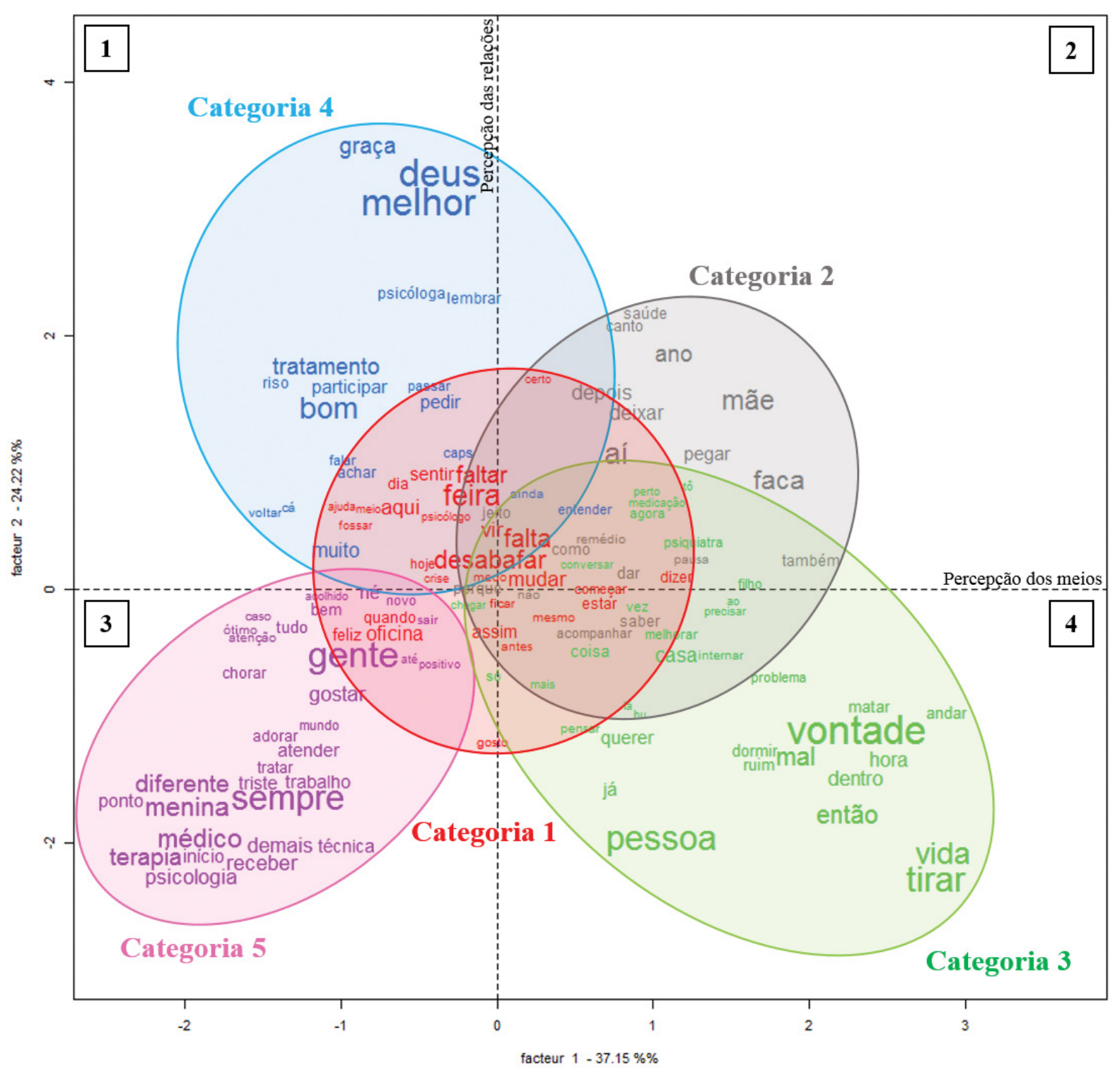

Figura 2.

Análise Fatorial de correspondência das categorias relacionadas aos elementos norteadores das oficinas, segundo as usuárias, gerada a partir da inserção de corpus textual das falas no Iramuteq.

Tabela 4.

Dados do software correspondentes ao corpus textual das falas de Técnicas de Referência.

\begin{tabular}{lc}
\hline DADOS & TOTAL \\
\hline Número de textos & 4 \\
Número de segmentos de textos & 158 \\
Número de formas distintas & 1.035 \\
Número de ocorrências & 5.481 \\
Média das formas por segmento & 34,68 \\
Número de categorias & 5 \\
Retenção de segmentos de texto & $120(75,95 \%)$ \\
\hline
\end{tabular}

Na Figura 3, observa-se que o dendograma apresenta as partições feitas no corpus até que as categorias finais fossem alcançadas. Então, de modo semelhante ao corpus Usuárias, o corpus Técnicas de Referência teve sua primeira partição em dois subcorpus, os quais também indicam a existência de dois grupos principais de elementos norteadores das oficinas, para as respectivas respondentes. O primeiro deles é composto pelas categorias 2 (Atenção Integral/18,3\%) e 1 (Percepção da Proposta/14,2\%), as quais passam pela segunda partição que dá origem à categoria 4 (Oficinas no Projeto Terapêutico/20,0\%). Neste grupo, observa-se a exis- 


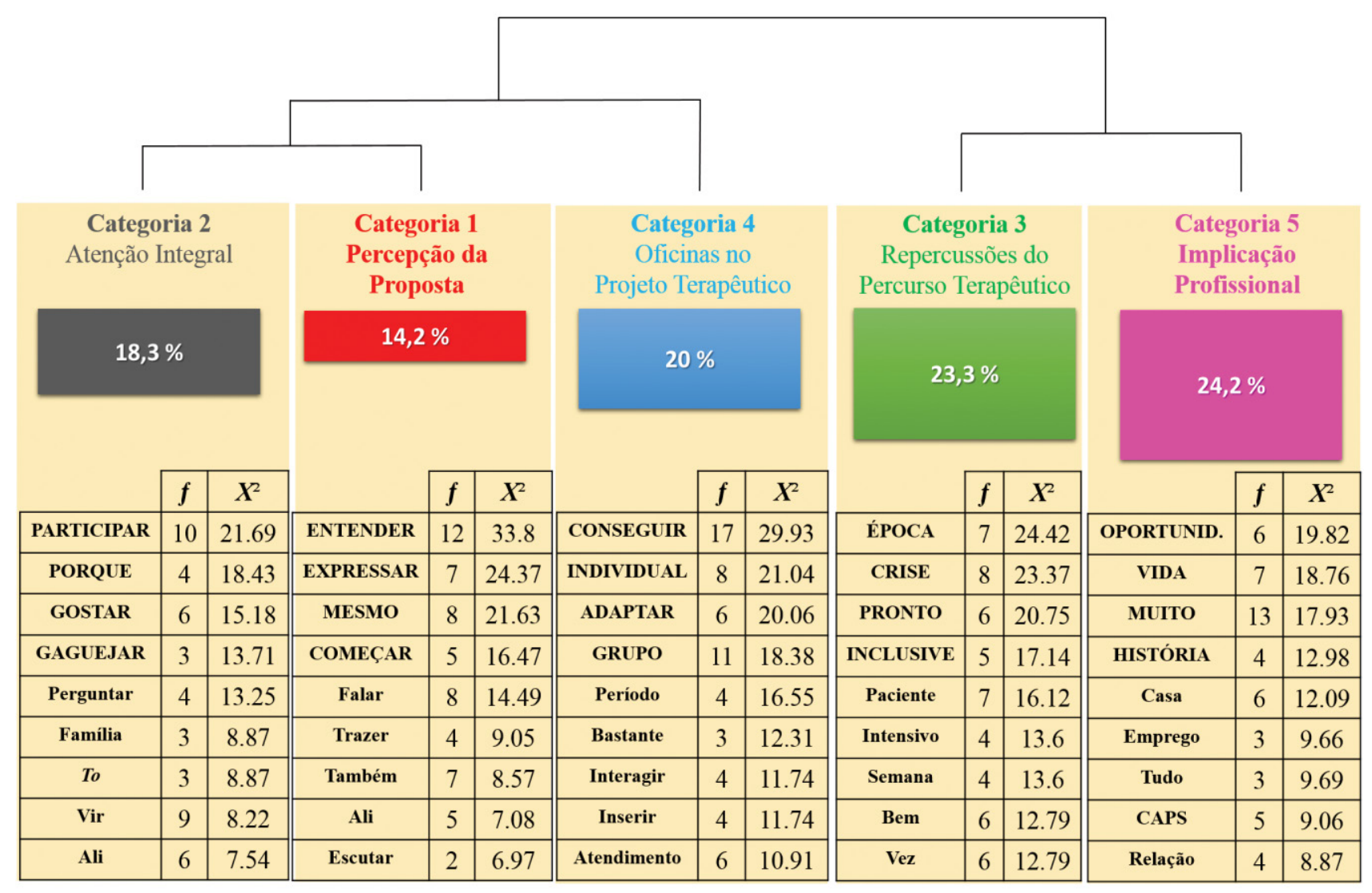

Figura 3.

Dendograma das categorias relacionadas aos elementos norteadores das oficinas, segundo as Técnicas de Referência, gerado a partir da inserção de corpus textual das falas no Iramuteq.

tência da circularidade de discursos que sugerem a pertinência da agregação/conexão da proposta das oficinas terapêuticas dialógicas às outras modalidades de atendimentos do Projeto Terapêutico também endereçadas às usuárias, a exemplo do cuidado de caráter intensivo, medicamentoso, individual, em grupo e às suas respectivas famílias. Destacam-se, então, estes segmentos textuais:

Acompanhamento familiar e acompanhamento em oficina... o projeto terapêutico dela foi trabalhar em oficinas [...] exatamente essa questão do uso dessa medicação, porque ela queria tomar a medicação toda quando ela tinha uma raiva. Quando ela brigava, ela tomava a medicação toda (Categoria 2, TR 2).

[...] ela, então, nesse momento de crise, [...] ficou no intensivo. Daí, eu comecei a trabalhar a questão dela participar das oficinas” (Categoria 2, TR 3). “[...] diante do transtorno mental, né, algumas pessoas não conseguem assim... [...] como é que eu posso dizer... falar... se expressar. E, dentro da proposta de vocês, eles conseguiram se expressar" (Categoria 1, TR 3). “Ela sempre trazia: 'eu posso conversar?', 'eu posso falar?', 'eu posso falar?'. E eu sempre trazia: 'Pode. Deve! É nessas oficinas que você vai conseguir expressar'” (Categoria 1, TR 4).

“Não. Não uma questão de obrigação, mas uma questão de tente hoje. Vamos ver o que vai acontecer se no final você gostar", pra gente tentar exatamente inseri-la naquele momento, naquele contexto. Ela se adaptou mais pelo... pelo momento de reflexão que vocês faziam. No final é que acontecia, culminava com uma atividade né. [...] eu observei que ela assim interagiu melhor, conseguiu permanecer mais algumas vezes na oficina, ela participou do grupo com assim... com um pedido meu eu dizendo: "vamos tentar". É... 
se tivesse continuado o grupo com vocês eu acredito que teria sido melhor. Mas, infelizmente, ela não consegue aderir às oficinas terapêuticas, as atuais. Ela não consegue, pois ela não consegue... infelizmente [...] (Categoria 4, TR 3).

Considerando estes segmentos de falas das TR, a literatura de Políticas Públicas de Saúde Mental reitera a responsabilidade compartilhada entre Técnicas(os) e Usuárias(os) acerca do monitoramento conjunto quanto aos desdobramentos do Projeto Terapêutico, também construído em parceria. Desta maneira, as(os) TR são responsáveis pelo acompanhamento da frequência das(os) usuárias(os) no serviço, bem como pelo contato com suas famílias por uma via que privilegie o diálogo (Brasil, 2004). Então, dentro do respeito das possibilidades de cada usuária, indica-se que as oficinas terapêuticas dialógicas integraram seus Projetos Terapêuticos como uma das apostas das TR enquanto espaço à fomentação de trocas que poderiam culminar no favorecimento de vínculos e interação humana, com a fala das usuárias enquanto uma das ferramentas de abertura ao protagonismo em suas próprias vidas, o que entra em consonância com o posicionamento de Constantinidis, Cid, Santana e Renó (2018) acerca da necessidade de uma prática profissional cotidiana de assistência que seja refletida, a fim de promover autonomia e desinstitucionalização daqueles que se encontram em sofrimento psíquico. Ademais, sobre o exercício da subjetividade, a psicanálise indica que "Algo mais está [...] envolvido na vida mental do indivíduo [...] de maneira que, desde o começo, a psicologia individual, nesse sentido ampliado mas inteiramente justificável das palavras, é, ao mesmo tempo, também psicologia social" (Freud, 1976, p. 91).

Já o segundo grupo é composto pelas categorias 3 (Repercussões do Percurso Terapêutico/23,3\%) e 5 (Implicação Profissional/24,2\%). Neste caso, identificam-se segmentos de falas cujo contexto sugere atuação profissional das TR e as usuárias enquanto partes que formam vínculo junto ao serviço substitutivo, viabilizando a emergência do tratamento, como apontam os discursos:

Era uma paciente grave [...]. Ela faz cinco anos se eu não me engano que está no serviço [...]. De início, [...] a gente marca a consulta. Faz o acolhimento [...] e, a partir do acolhimento, dependendo do caso [...] agiliza na questão das [...] consultas médicas. Então, ela mesmo [...] tendo sido encaminhada da emergência, [...] a gente fez essa consulta e foi prescrito as medicações e as terapias. Inclusive, ela ficou no intensivo na época. [...] depois, [...] ela foi evoluindo bem. Foi aceitando o tratamento e aí a gente determinou duas vezes na semana. [...] hoje, ela encontra-se quinzenalmente. [...] foi maravilhosa essa oficina que vocês fizeram. Inclusive, nossa equipe toda a gente comentou, em reunião [...]. Inclusive, eles ainda hoje perguntam: '[...] e aquela oficina daqueles meninos? Como é que vai ser?' (Categoria 3, TR 1).

“Em virtude da saída de médicos, [...] de pessoas do quadro do grupo que ela tava inserida, ela já se distanciou um pouco" (Categoria 3, TR 4). "O CAPS é tudo pra mim. Eu... eu trabalho no trauma e costumo dizer às meninas, sabe, que Saúde Mental ensina muito a gente" (Categoria 5, TR 1).

Pela oportunidade que eu tive de ajudar, eu usei como uma terapia pra mim. Você tá entendendo? [...] quando eu venho aqui pra o CAPS eu digo: 'hoje eu vou fazer a minha terapia'. [...] cada pessoa que entra aqui eu tento transforma-la também no que me transformei, quando eu entrei aqui. [...] e eu transformei no meu trabalho, assim (Categoria 5, TR 3).

Nestas falas, observa-se a circulação de diferentes formas do estabelecimento de vínculos, tanto às TR (implicação profissional) quanto às usuárias (repercussões terapêuticas), ditos que, por vezes, incluem as oficinas dialógicas neste movimento. Assim, recorre-se à literatura psicanalítica que trabalha a noção de vínculo a partir do conceito de identificação. Nesta perspectiva, faz-se uso da acepção que corresponde à forma reflexiva do verbo "identificar", obtendo-se a expressão identificar-se. Como sugere Nasio (1999), o sujeito passa pelo processo de identificação com algo ou alguém quando ele se confunde com estes, dirigindo-se ao outro não apenas para assimilá-lo, mas para assimilar-se a ele, até tornar-se idêntico. No entanto, ressalta-se que este processo ocorre sob a emergência de um impulso espontâneo e irrefletido, banhado pelo estabelecimento de um "elo de amor", desenvolvendo-se, em segundo momento, o que a psicanálise nomeia de transferência. 
A seguir, na Figura 4, vislumbra-se o gráfico de AFC referente às palavras-chave acerca dos elementos norteadores das oficinas, nos discursos trazidos pelas TR. Neste caso, aprecia-se o gráfico de AFC na perspectiva em que a linha do eixo horizontal divide as categorias a partir da noção de percepção de vínculo, cujo bloco superior (quadrantes 1 e 2) indica a concentração da apreensão do vínculo junto à equipe do CAPS, com composição a partir das categorias: 1 (Percepção da Proposta), 4 (Oficinas no Projeto Terapêutico) e 5 (Implicação Profissional), cujas falas referenciam a influência dos atores, de convívio próximo e que trabalham no CAPS, acerca do tratamento das usuárias. Enquanto isso, o bloco inferior (quadrantes 3 e 4) indica a concentração da apreensão do vínculo junto aos contextos e circunstâncias extra CAPS, com composição a partir das categorias 2 (Atenção Integral) e 3 (Repercussões do Percurso Terapêutico), cujos endereçamentos das falas das TR estão voltados aos contextos e eventos sociais vivenciados pelas usuárias, com repercussão em seus respectivos tratamentos. Já a linha do eixo vertical divide

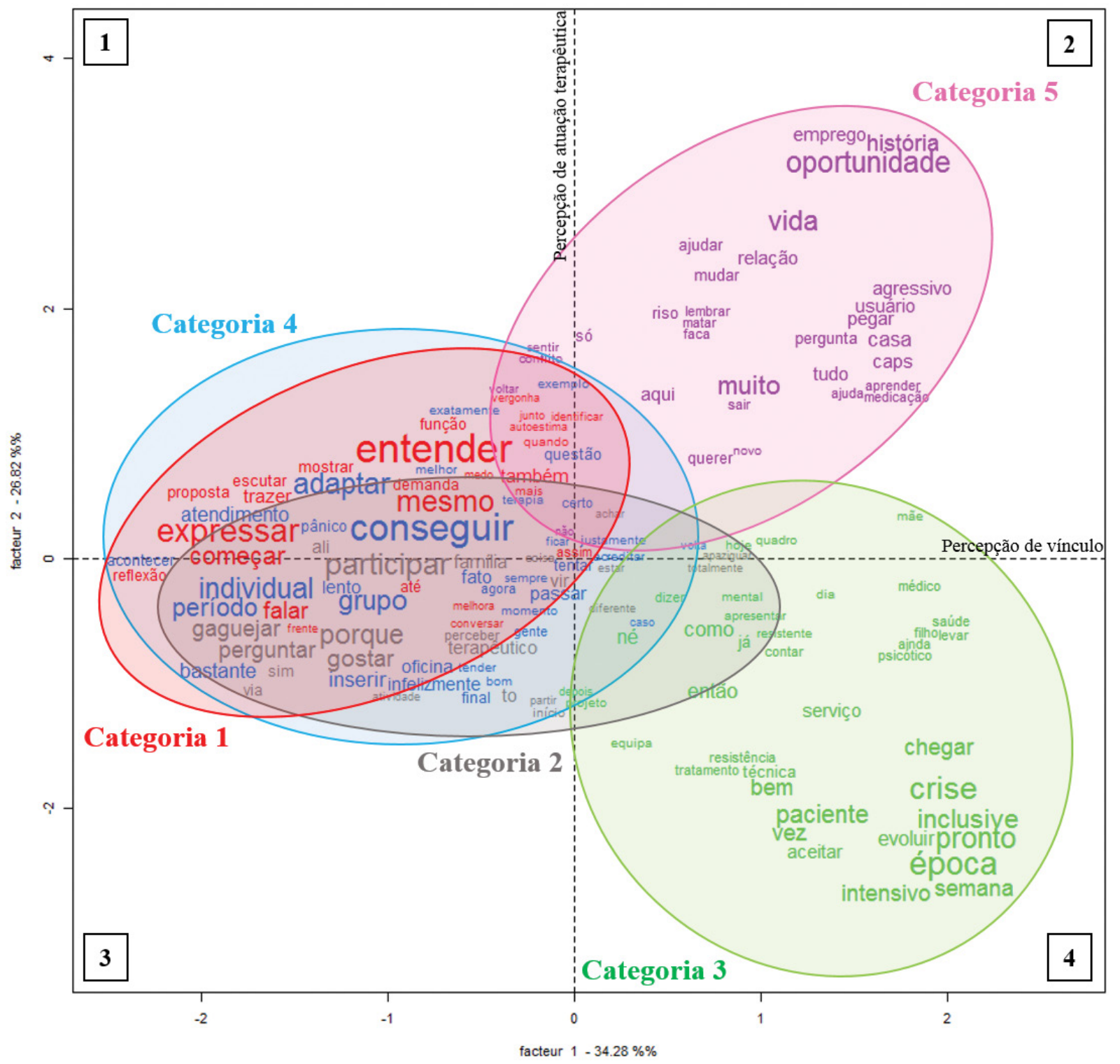

Figura 4.

Análise Fatorial de correspondência das categorias relacionadas aos elementos norteadores das oficinas, segundo as Técnicas de Referência, gerada a partir da inserção de corpus textual das falas no Iramuteq. 
as categorias a partir da noção de percepção de atuação terapêutica, cujo bloco esquerdo (quadrantes 1 e 3) indica a concentração da atuação das usuárias no próprio processo, com composição a partir das categorias 1 (Percepção da Proposta), 4 (Oficinas no Projeto Terapêutico) e 2 (Atenção Integral), com falas das respondentes que indicam a parcela de iniciativa e participação advindas das próprias usuárias, bem como de suas respectivas famílias. E o bloco direito (quadrantes 2 e 4) indica a concentração da atuação da equipe do CAPS na condução do tratamento, com composição a partir das categorias 5 (Implicação Profissional) e 3 (Repercussões do Percurso Terapêutico), cujos segmentos textuais apontam às falas direcionadas principalmente à influência e responsabilidade exercidas por aqueles que atuam no CAPS, em relação ao tratamento das usuárias, sejam da equipe de técnicos ou de equipes que se disponham a agregar ao serviço, a exemplo das oficinas dialógicas que ocorreram a partir de um trabalho de atuação em extensão universitária.

Observa-se, assim, novas possibilidades de inscrições do sofrimento mental, diferente de momentos não muito longínquos da história, em que os diagnósticos da chamada "loucura" esteve sob o controle da atenção hospitalocêntrica e manicomial, causando o que Moffatt (1984) chamou de amputações nas pessoas, cuja reverberação se encontrava na retirada do direito às vestimentas, alimentação, fala e do sentimento de pertencer à sociedade. Ainda segundo o autor, o próprio corpo de cada sujeito era a última propriedade ou instrumento que restava enquanto veículo à comunicação de mensagens que demonstravam seus sentimentos de vida no hospício, passando por atitudes e deformações corporais e até mesmo processos de somatização, com agravação dos quadros. Em relação a este procedimento manicomial de controle do outro, cita-se o que Foucault (2013) nomeou de docilização dos corpos, noção que já se apresentava de maneira incipiente quando o mesmo autor debateu o processo de higienização social, em A história da loucura:

[...] o internamento, em suas formas primitivas, funcionou como um mecanismo social [...]. Daí a supor que o sentido de internamento se esgota numa obscura finalidade social que permite ao grupo eliminar os elementos que lhe são heterogêneos ou nocivos, há apenas um passo. [...] a era clássica teria neutralizado, com segura eficácia - tanto mais segura quanto cega - aqueles que, não sem hesitação, nem perigo, distribuímos entre prisões, casas de correção, hospitais psiquiátricos ou gabinetes de psicanalistas (Foucault, 2012, p. 79).

Desta forma, recorre-se à Nietzsche (2010), complementando a fala de Foucault ao associar o entorpecimento da dificuldade de captar novas nuances à miopia crônica que, ao se deparar com horizontes mais amplos, escolhe se agravar até a cegueira. Assim, diferentemente destes paradigmas manicomiais de séculos passados, os aparelhos substitutivos advindos da Reforma Psiquiátrica inserem o usuário em novo campo, o do reconhecimento de suas dimensões subjetivas, humanas e sociais. Neste ensejo, faz-se relevante trabalhar a "cura" a partir de outros vieses, a exemplo da perspectiva sugerida por Herrmann (1984) em que "estar curado" significa "curar si mesmo", atingindo momento semelhante ao de uma fruta que amadurece ou de um queijo bem curado, que atinge o ponto. Seguindo a reflexão, o autor ainda ressalta que os pontos variam de um queijo para outro, assim como de uma pessoa para outra, resultando no alcance das potencialidades do queijo, bem como da pessoa.

Desta forma, apreende-se do dendograma com categorias da CHD, dos discursos das usuárias, a função terapêutica da fala enquanto veículo à expressividade e o autodirecionamento do tratamento, com emersão da autonomia. Ademais, acrescenta-se os dados trazidos pelo dendograma com categorias da CHD, referente às falas das TR, que abordam o reconhecimento da viabilidade de inserção das oficinas dialógicas aos respectivos Projetos Terapêuticos destas usuárias. Nesta perspectiva, traz-se à discussão o que Herrmann (2001) chama de zona intermediária, a partir da psicanálise, bem como o que Bock (2009) problematiza enquanto subjetividade social, no tema Psicologia e compromisso social, ambos destacando a subjetividade como um sistema que se expressa simultaneamente nas esferas intrapsíquica e social, de forma dialética. Nesse momento, considera-se importante mencionar essas duas instrumentalizações teórico-práticas enquanto saberes que se complementam mutuamente, caracterizando a possível transversalidade na qual Psicanálise e Psicologia Sócio-Histórica não se opõem, mas unem-se à pos- 
sível promoção de uma clínica ampliada com potenciais efeitos terapêuticos. Assim, observam-se estes desdobramentos principalmente no dendograma com categorias da CHD, das falas de usuárias, com o contexto sociofamiliar enquanto componente que atravessou seus ditos ao longo das oficinas dialógicas, cujo "falar sobre" repercutiu em seus tratamentos. Isto também se observa na AFC dos ambientes textuais de seus discursos, com destaque às suas percepções dos meios interno e externo e das relações nos níveis individual e social.

Portanto, fala-se na corrente de pensamento da Psicologia que está pautada na libertação daqueles que se encontram na posição de oprimidos, bem como daqueles que se encontram na condição de opressores, a partir da práxis psicossocial também aplicada à Saúde Mental. Assim, fala-se que a libertação, "O respeito à autonomia e à dignidade de cada um é um imperativo ético e não um favor que podemos ou não conceder uns aos outros" (Freire, 2014, p. 58). Corroborando esta reflexão, a AFC dos ambientes textuais dos discursos das TR destaca a percepção de atuação das usuárias no próprio processo terapêutico, além das próprias profissionais, o que sugere existência de autonomia das usuárias entrevistadas para se aperceberem e atuarem nas relações de vínculos e circunstâncias intra e extra CAPS, fatores que repercutem na evolução do tratamento.

Ademais, cita-se o material do dendograma com categorias da CHD, referente às falas das TR, que traz a identificação profissional daqueles que atuam no CAPS, com alguns discursos também associados à prática das oficinas dialógicas levadas pelos extensionistas, enquanto importante parcela que repercute no tratamento das usuárias. Desta forma, a respeito da conduta daqueles que atuam junto à subjetividade do sujeito em grupo através da fala, o texto $A$ perspectiva futura da terapêutica psicanalítica lembra:

O sucesso que o tratamento pode ter com o indivíduo, deve ocorrer, igualmente, com a comunidade. [...] estarão, não apenas dando aos seus pacientes remédio mais eficaz para os seus sofrimentos, de que dispõem hoje em dia; estarão contribuindo, com a sua parcela, para o esclarecimento da comunidade [...] (Freud, 1970, p. 133 e 135).

Apreende-se, aqui, a pedra angular sobre a qual repousa a função terapêutica das oficinas, através do espaço à fala: o esclarecimento daqueles que compõem a comunidade acerca dos fenômenos de suas próprias subjetividades, expandindo este termo às últimas consequências.

Ainda sobre a AFC de ambientes dos discursos das TR, acrescenta-se o destaque aos dados que demonstram existência de implicação profissional daqueles que atuam no CAPS, com inclusão dos estudantes responsáveis pelas oficinas dialógicas, criando-se elos entre quem atende e quem é atendido. Esta implicação, segundo Brasil (2004), surge a partir da equipe que almeja organização, desenvolvimento e manutenção do ambiente em que a terapêutica ocorre, sinalizando que a permanência do usuário não depende apenas de seu comprometimento psíquico junto ao tratamento, mas também das formas de estabelecimento de vínculos terapêuticos com a equipe técnica, relações que ocorrem em "via dupla".

A este respeito, a literatura psicanalítica traz a contribuição a partir do que André Green, em seu livro Orientações para uma Psicanálise contemporânea, nomeia de Terceiridade, chamando atenção às construções simbólicas que se dão a partir dos encontros entre os sujeitos, seja em seu seio familiar, setting terapêutico ou nas demais formas de relações, como em oficinas terapêuticas. Ao atentar à discussão do Terceiro, o autor menciona uma metáfora para demonstrar a simbologia da emergência de um terceiro que existe entre quem atende e quem é atendido, situação comparada a um objeto que é cortado em dois, ao mesmo tempo constituindo um sinal de reconhecimento quando os portadores destas metades podem juntar os dois pedaços (Soares, 2014).

Desta forma, apreende-se que a fala é elemento que se posiciona na construção deste Terceiro, onde o corpo não se encontra mais enquanto último instrumento de expressividade reprimida. Portanto, a escuta daqueles que falam se caracteriza enquanto posição de reconhecimento radical do saber que cada sujeito carrega acerca de sua própria história. Neste contexto de discussão dos dados da realidade, concorda-se com Neiva (2010) quanto à reiteração da importância de uma ação que se desdobra em pesquisa, redundando em nova ação que pode sugerir ideias de mudança, transformação e até mesmo de libertação, referente às representações deturpadas de "loucura" criadas historicamente pela sociedade, bem como pelos próprios usuários que nela se encontram inseridos. 


\section{Conclusão}

A partir dos resultados alcançados, elucida-se a necessidade de diálogos constantes voltados à Saúde Mental, a fim do alcance de práticas que possibilitem atuação e pesquisa que melhor respondam às demandas comunitárias. Diante disto, reitera-se a indispensabilidade do diálogo acontecer não apenas sobre o CAPS, mas dentro do CAPS, junto àqueles que fazem parte da Unidade, seja enquanto profissionais, usuários ou familiares. Assim, identificou-se o formato de oficina terapêutica dialógica como proposta possível e viável de atuação que consegue servir de veículo à expressão pela fala, a qual pode transportar conteúdos passíveis de intervenção, sejam de ordem emocional-afetiva ou de dimensões sociais. Além disto, a pesquisa atingiu seus objetivos, sinalizando a importância de buscar nos próprios sujeitos da sociedade respostas às inquietações teóricas, o que pode viabilizar o melhor conhe- cimento da realidade local, afinando abordagens que melhor se encaixem no fazer proposto pela Reforma Psiquiátrica. No entanto, apesar deste êxito, chama-se atenção à limitação ocasionada pela variável tempo, a qual se expressa na existência de quase dois anos entre a finalização das oficinas terapêuticas dialógicas, desenvolvidas em extensão universitária, e a realização da coleta dos dados. Neste intervalo, compreende-se a ocorrência de eventos, como alta de usuários ou processo de desligamento dos atendimentos por outros motivos, o que impossibilitou o acesso a estes e às suas experiências nas oficinas e no período pós-CAPS. Desta forma, aponta-se à necessidade de futuras investigações que melhor abarquem outros fenômenos vivenciados por usuários e que possam estar vinculados ao processo de desligamento do serviço, já que este momento simboliza uma ruptura que anuncia momento inaugural na vida dos egressos.

\section{Referências}

Azevedo, D. M., \& Miranda, F. A. N. (2011). Oficinas terapêuticas como instrumento de reabilitação psicossocial: Percepção de familiares. Escola Anna Nery, 15(2), 339-345. https://doi.org/10.1590/S141481452011000200017

Brasil. Ministério da Saúde. (2004). Saúde mental no SUS: Os centros de atenção psicossocial. Brasília, DF: o autor.

Breuer, J. \& Freud, S. (1995). Casos clínicos. In J. Breuer, \& S. Freud, Estudos sobre a histeria (pp. 57-202). Rio de Janeiro, RJ: Imago.

Camargo, B. V., \& Justo, A. M. (2013). IRAMUTEQ: um software gratuito para análise de dados textuais. Temas em Psicologia, 21(2), 513-518.

Campos, E. B. V. (2007). Sobre a atualidade do mal-estar. Psychê, 11(20), 185-189.

Coelho, R. S., Velôso, T. M. G., \& Barros, S. M. M. (2017). Oficina com usuários de saúde mental: A família como tema de reflexão. Psicologia: Ciência e Profissão, 37(2), 489-499. https://doi.org/10.1590/1982-3703002612015

Conselho Federal de Psicologia - CFP. (2013). Referências técnicas para atuação de psicólogas(os) no CAPS. Brasília, DF: o autor.

Constantinidis, T. C., Cid, M. F. B., Santana, L. M., \& Renó, S. R. (2018). Concepções de profissionais de saúde mental acerca de atividades terapêuticas em CAPS. Trends in Psychology, 26(2), 911-926. https://doi.org/10.9788/ tp2018.2-14pt

Foucault, M. (2012). O mundo correcional. In M. Foucault, História da loucura (pp. 79-109). São Paulo, SP: Perspectiva.

Foucault, M. (2013). Os corpos dóceis. In M. Foucault, Vigiar e punir: História da violência nas prisões (pp. 131-163). Petrópolis, RJ: Vozes.

Freire, P. (2014). Ensinar não é transferir conhecimento. In P. Freire, Pedagogia da autonomia: Saberes necessários à prática educativa (pp. 47-87). Rio de Janeiro, RJ: Paz e Terra.

Freud, S. (1970). As perspectivas futuras da terapêutica psicanalítica. In S. Freud, Cinco lições de psicanálise, Leonardo da Vinci e outros trabalhos (pp. 125-136). Rio de Janeiro, RJ: Imago.

Freud, S. (1976). Psicologia de grupo e análise do ego. In S. Freud, Além do princípio de prazer, psicologia de grupo e outros trabalhos (pp. 87-179). Rio de Janeiro, RJ: Imago. 
Freud, S. (1989). Construções em análise. In S. Freud, Moisés e o monoteísmo, esboço de psicanálise e outros trabalhos (pp. 289-304). Rio de Janeiro, RJ: Imago.

Gomes, A. A. (2009). Linguagem e discurso na psicanálise de Jacques Lacan. Revista Iluminart, 1(2), 1-9.

Herrmann, F. (1984). A cura psicanalítica. In F. Herrmann, O que é psicanálise (pp. 97-107). São Paulo, SP: Brasiliense.

Herrmann, F. (2001). Zona intermediária. In F. Herrmann, Introdução à teoria dos campos (pp. 19-27). São Paulo, SP: Casa do Psicólogo.

Jesus, D. M. (2010). O que nos impulsiona a pensar a pesquisa-ação colaborativo-crítica como possibilidade de instituição de práticas educacionais mais inclusivas? In C. R. Baptista, K. R. M. Caiado, \& D. M. Jesus (Orgs.), Educação especial: Diálogo e pluralidade (pp. 139-159). Porto Alegre, RS: Mediação.

Marconi, M. A., \& Lakatos, E. M. (2008). Técnicas de pesquisa. In M. A. Marconi, \& E. M. Lakatos, Fundamento de metodologia científica (pp. 176-216). São Paulo, SP: Atlas.

Martínez, A. M. (2009). Psicologia e compromisso social: Desafios para a formação do psicólogo. In A. M. B. Bock (Org.), Psicologia e o compromisso social (pp. 143-160). São Paulo, SP: Cortez.

Mello, M. F., Mello, A. A. F., \& Kohn, R. (2007). Reforma psiquiátrica e política de saúde mental no Brasil. In M. F. Mello, A. A. F. Mello, \& R. Kohn (Orgs.), Epidemiologia da saúde mental no Brasil (pp. 39-79). Porto Alegre, RS: Artmed.

Moffatt, A. (1984). Os hospícios: Estrutura e ideologia manicomial. In A. Moffatt, Psicoterapia do oprimido: Ideologia e técnica da psiquiatria popular (p. 15). São Paulo, SP: Cortez.

Nasio, J. D. (1999). O conceito psicanalítico de identificação. In J. D. Nasio, O prazer de ler Freud (pp. 80-84). Rio de Janeiro, RJ: Jorge Zahar.

Neiva, K. M. C. (2010). O que é intervenção psicossocial? In K. M. C. Neiva, Intervenção psicossocial: Aspectos teóricos, metodológicos e experiências práticas (pp. 13-23). São Paulo, SP: Vetor.

Nietzsche, F. (2010). Os instintos, metamorfoses da vontade de potência. In F. Nietzsche, Vontade de potência (pp. 409-430). São Paulo, SP: Escala.

Soares, B. H. (2014). O terceiro analítico no divã. In Universidade Estadual da Paraíba - UEPB, Círculo de estudos em metapsicologia e epistemologia psicanalítica. Campina Grande, PB: o autor.

Bruno Henrique Soares

Psicólogo graduado pela Universidade Estadual da Paraíba - CAMPUS I, Campina Grande-PB e Mestrando pelo Programa de Pós-Graduação em Psicologia Clínica do Instituto de Psicologia da Universidade de São Paulo (IPUSP)

- CAMPUS CAPITAL, São Paulo-SP. Brasil.

E-mail: brunno_hennrique@hotmail.com

(iD https:// orcid.org/0000-0001-8690-9589

Andréa Xavier de Albuquerque de Souza

Professora Doutora efetiva do Departamento de Psicologia da Universidade Estadual da Paraíba, Campina Grande - PB. Brasil.

E-mail: deaxavi@yahoo.com.br

(iD) https:// orcid.org/0000-0001-6796-9930

Farah Catharine de Queiroz Silva

Psicóloga graduada pela Universidade Estadual da Paraíba - CAMPUS I, Campina Grande-PB e cursando Pós-Graduação/Especialização em Saúde Mental e Atendimento Psicossocial-UNICORP; Pós-Graduação/ Especialização em Psicopedagogia Clínica e Institucional-CBI of MIAMI.

E-mail: farahcatharine2@gmail.com

(iD) https:// orcid.org/0000-0002-6788-2218 


\section{Márcia Candelaria da Rocha}

Professora Mestra substituta do Departamento de Psicologia da Universidade Estadual da Paraíba, Campina Grande - PB. Brasil.

E-mail: marciacandelaria12@hotmail.com

(iD) https://orcid.org/0000-0002-1071-5937

\section{Pablo Leonardo de Melo}

Psicólogo graduado pela Universidade Estadual da Paraíba - CAMPUS I, Campina Grande-PB e Mestrando pelo Programa de Pós-Graduação em Psicologia da Saúde do Departamento de Psicologia da Universidade Estadual da Paraíba. Brasil.

E-mail: pablo.psi016@gmail.com

(iD) https://orcid.org/0000-0003-4925-1700

Viviane Almeida Cavalcanti

Psicóloga graduada pela Universidade Estadual da Paraíba - CAMPUS I, Campina Grande-PB. Brasil.

E-mail: vivianepha@gmail.com

(iD) https://orcid.org/0000-0002-8840-0935

Endereço para envio de correspondência:

Rua Baraúnas, 351, Bairro Universitário, CEP: 58.429-500. Campina Grande - PB. Brasil.

Recebido 19/11/2017

Reformulado 01/10/2018

Aceito 31/10/2018

Received 11/19/2017

Reformulated $10 / 01 / 2018$

Approved 10/31/2018

Recibido 19/11/2017

Reformulado $01 / 10 / 2018$

Aceptado $31 / 10 / 2018$

Como citar: Soares, B. H., Souza, A. X. A., Silva, F. C. Q., Rocha, M. C., Melo, P. L. \& Cavalcanti, V. A. (2019). Efeitos terapêuticos de oficinas dialógicas: a fala em contexto de reforma psiquiátrica. Psicologia: Ciência e Profissão, 39, 1-18. https://doi.org/10.1590/1982-3703003188051

How to cite: Soares, B. H., Souza, A. X. A., Silva, F. C. Q., Rocha, M. C., Melo, P. L. \& Cavalcanti, V. A. (2019). Therapeutic effects of dialogical workshops: the voice in the context of psychiatric reform. Psicologia: Ciência e Profissão, 39, 1-18. https://doi.org/10.1590/1982-3703003188051

Cómo citar: Soares, B. H., Souza, A. X. A., Silva, F. C. Q., Rocha, M. C., Melo, P. L. \& Cavalcanti, V. A. (2019). Efectos terapéuticos de talleres dialógicos: el discurso en el contexto de la reforma psiquiátrica. Psicologia: Ciência e Profissão, 39, 1-18. https://doi.org/10.1590/1982-3703003188051 